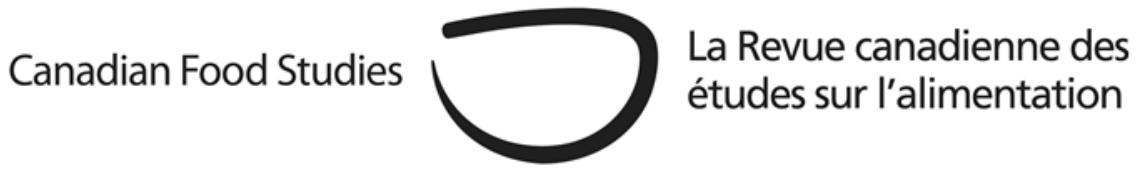

Research Article

\title{
Understanding and developing food pedagogies in Ontario pre- service education
}

\author{
Rachelle Campigotto*, Sarah Barrett, Rod MacRae
}

York University

\section{Abstract}

Policy documents implore Ontario teachers to integrate environmental education (EE) in the curriculum. Evidence of significant barriers such as lack of time, resources and knowledge, and lack of preparation at the Bachelor of Education level to teaching EE is well documented (Barrett, 2007, 2013; Stevenson, 2007; Thompson, 2004). Food literacy (FL) is often considered a framework from which to understand environmental issues, thus the authors sought to consider its' usefulness in aiding integration of EE curricula. Using a 'theory into practice' approach we asked: Can food literacy be used to make environmental issues more relevant and accessible, thus diminishing the barriers to teaching EE? How do pre-service teachers define FL and do they know enough to use this framework? Qualitative interviews were conducted with thirteen Ontario pre-service teachers to determine their understanding of FL. Findings included a lack of exposure to FL concepts, however, there was an interest to using FL to help teach EE. Some suggestions to improve food pedagogy in the pre-service program and placements included: curriculum changes that made explicit connection to food; clear linkages between environmental issues and food; empowering students to do projects, debates and assignments on food, and experiential learning. Ultimately, there was interest and promise of utilizing FL to integrate EE, but a change of culture at the pre-service level is needed for it to be supported.

Keywords: Food literacy; Ontario education; food pedagogy 
Introduction and Background

In this qualitative study, we consider how thirteen pre-service teachers in Ontario understand food literacy (FL) and its' relationship to environmental education (EE). This study also describes, from interviews with the pre-service teachers, their experiences with FL and EE in schools where they practice teach as part of their university program. Lastly, we discuss the possibility and effectiveness of FL as a tool to integrate EE into the curriculum as outlined as a goal in Ontario documents. The following sections provide an overview of food literacy literature, including the definitions and tensions of the term. We will place these terms and understandings in the context of education and how theoretical contexts impact practical nuances in pedagogy.

\section{Food literacy}

While food literacy remains "a concept under construction" (Sumner, 2013, p. 82) the interdisciplinary nature of food affords educators a variety of avenues to explore and make relevant linkages to the environment for their students (Valley et al., 2017). FL emphasizes the acquisition of knowledge related to food and includes six themes: skills and behaviours, food/health choices, culture, knowledge, emotions, and food systems (Truman et al., 2017). Food literacy considers many aspects of food from farm to table including cooking, eating healthy, knowledge, empowerment, engagement, culture, food security, and fun (Anderson, 2007). An important aspect of FL is recognizing the disconnect in our relationship with food and the resulting lack of nutritional knowledge, interest, and ability to prepare food (Lang \& Caraher, 2001; Short, 2003). The concept of literacies, in general, goes beyond language and includes a focus on context and situated knowledge (Frisch et al., 2012). Classens and Sytsma (2020) expand upon this idea of FL being both everyday and common, and with politically relevant connections to broader systemic issues that can be used to promote change within the food system. It is the interrogation of our relationship in choosing, preparing, and eating food that we can begin to unravel the literacies and hidden contexts behind food situated in environmental knowledge and education.

The complex nature of food systems suggests that without a critical approach to food pedagogy, it may be difficult to interrogate both ecological and social injustices (Flowers \& Swan, 2012; Jordan et al., 2014). Food, with its multidimensional nature and diverse conceptualizations, provides many avenues for a curriculum which integrates EE. Food intersects with several activist areas such as poverty, women's rights, and community organizing. Environmental educators engage with multiple issues, including social justice, as well as sociopolitical and economic factors, and sustainability thus linking to food pedagogy in many ways (Haugen, 2010). The interconnectedness of FL and EE allows students to explore realworld examples, such as poverty, racism, the environmental and social impact of factory farming, city planning that lacks affordable transportation and creates food deserts, and the 
community and social impact of cooking and gardening. As such, food is the "quintessential interdisciplinary subject" and an "entry point" into other disciplines (Barndt, 2012, p 70). Those engaging in food pedagogy can encounter and enhance their learning in areas including knowledge and skills in agricultural production, distribution, nutrition, and disposal of food waste, and in turn, understand the complex relationships between food safety and security, sustainability, and food sovereignty (Valley et al., 2017). Indeed, since every student has experience with food through eating habits, culture, and celebration, emphasizing FL in the classroom provides a platform to uncover the social justice, sociopolitical, and economic barriers to food access.

The classroom has been identified as an important locus of environmental learning (Russell \& Burton, 2000). There are multiple approaches and goals to EE, ranging from a focus on the skills necessary to understand the relationship between human and non-human animals, decision making, interdisciplinarity, informal education, varying scales from local place-based education to global environmental issues, food security, conservation and more (Stevenson, 2007). Studies have found that many pre-service teachers define EE as education about the environment (Evans et al., 2012) this view is often conservative (Fien, 2004) and technocratic (Robottom, 1987), labelling the environment as something "out there" that humans can manipulate and control.

Pre-service teachers may be exposed to EE in various capacities. In their own education prior to entering the education department many elementary and secondary schools in Ontario take part in Ontario EcoSchools "a certification program for grades K-12 that helps school communities develop both ecological literacy and environmental practices, to become environmentally responsible citizens and reduce the environmental footprint of schools" (Ontario EcoSchools, 2019). EcoSchools often have an EcoTeam that focuses on activities based learning and physical changes such as "greening" the school (Ontario EcoSchools, 2019). The effectiveness of such interventions at transforming environmental attitudes, and the overall value of introducing EE is still being questioned (Brodie, 2017). Additional exposure may be through the Ontario government implemented Environmental Studies Programs (ESPs) which started in 2002 and provides specialized environmentally-focused student curriculum in Ontario public schools (Breunig et al., 2014). The pre-service curriculum aims to integrate policy documents including those pertaining to environmental education; there is also some mention of practicum reflection in relation to Indigenous Education and environmental concerns such as health (OCT, 2017). It is the goal that pre-service teachers leave the education program "advancing social responsibility and environmental citizenship" (OCT, 2017, p.35). School specific curriculum may include special topics courses around environmental education principles or certificate programs such incorporating sustainability education alongside an education degree (York University, 2021; OCT, 2017).

Lastly, there are various policies and curricula exist providing support for integrating EE (Ontario Ministry of Education, 2007, 2009). Integration is useful because it includes real-world experiences that make learning authentic to students' lives and links subject matter across the 
curriculum (Breunig \& O'Connell, 2008). While teachers support the effort to integrate and teach EE, they face barriers to successfully doing so, such as a lack of time to adequately address the subject appropriately even with its interdisciplinary qualities (Barrett, 2007; Barrett, 2013; Stevenson, 2007; Thompson, 2004). Research suggests that in the absence of specialized EE training, which is the present situation in Ontario, teachers and pre-service teachers lack confidence to provide environmental education and take appropriate action in their pedagogy (Rogan, 1999; Stir, 2006; Tuncer et al., 2009). Here, we focus on the relationship between EE and FL as a pedagogical tool to help with integration of EE curriculum (Barrett, 2017; Campigotto \& Barrett, 2017; Stevenson, 2007).

\section{Food and education}

Using food as a window into environmental issues (Barndt, 2012) may provide an opportunity to integrate EE. Placing FL in education calls for a situated definition, within an environmental context, with cross-relationships to sociocultural factors, food security, food skills and health (Cullen et al., 2015). The authors consider this wider scope to make connections for developing teachers in an integrated curriculum. Sumner's (2013) work resonated specifically with our exploration of food literacy in education - the concept of "reading the world through eating". We see food as a pedagogical act that encompasses social and environmental aspects, starting from growth, to processing, to consumption but also includes what we learn from the act of eating (Sumner, 2013). It places a personal connection to one's own eating habits, education and learning processes, as well as expands the idea of learning about, in, and through what we eat daily.

Unfortunately, pre-service teachers' understanding of FL is currently underexplored. There is some research, especially in Australia, that considers food education as part of preservice education, however, like Canada, there have been no large-scale studies to investigate FL in this area (Elsden-Clifton \& Futter-Puati, 2015). A study of 126 pre-service student teachers considered knowledge of food in relation to spaces: health, sustainability, and a combined health/food education. Despite making the connection between food and sustainability clear in the health curriculum, pre-service teachers continued to focus on health-only aspects of food, such as obesity, and rhetoric of good and bad food choices and struggled to expand their reflections to link sustainable practices and well-being (i.e., recycling, cleaner air), and cultural practices of food within families (Elsden-Clifton \& Futter-Puati, 2015). In a classroom, teachers can help create a positive food environment through cooking and gardening, which often improves fruit and vegetable consumption, and food knowledge (Brown \& Hermann, 2005; Cutter \& Smith, 2001; Gray, \& Goodell, 2015; Meehan et al., 2008; Mita et al.). In the Ontario education system, the topic of food tends to be approached through the lens of eating and preparation, with a strong emphasis on breakfast programs and healthy lunch initiatives (Sustain Ontario, 2013; Ontario Student Nutrition Program, 2016). One of the challenges of implementing 
FL is a teacher's willingness to explore food related topics, such as agriculture. For example, Knobloch (2008) found that teachers would explore food through the areas of agriculture and sustainability if they could see the value to, and the fit with their curriculum. Another study evaluated the implementation of food literacy curriculum, and found that while teachers were enthusiastic and willing, they lacked confidence and needed more awareness and resources (Nanayakkara et al., 2018).

By using concepts of FL as a window into environmental issues (Barndt, 2012), we seek to explore the possibility of harmonizing FL and EE at the pre-service stage. We aim to answer the following questions: Can food literacy be used to make environmental issues more relevant and accessible, thus diminishing the barriers to teaching EE? Do pre-service teachers know enough about food literacy to use this framework the literature supports? How do they define FL? And how can the pre-service program support them?

\section{Methodology}

We chose to focus on the experiences of pre-service teachers in their own words using a social constructivist approach, based on Creswell and Miller's (2000) guiding framework, to gain insight into how pre-service teachers make sense of their teacher education experiences. Following Creswell's (2013) model, the authors honoured the participants' views as complex and authentic, informed by places and experiences they encountered during their education and activism, either currently or historically. Participants were recruited through email, class visits, and social media. Two participants, as disclosed on the ethics report, were former students of one researcher. To be included in the study individuals must be enrolled in the education department at any level, and have a background, passion, or interest in environmental issues. These teacher candidates were sought because they had some knowledge or interest in the area. We aimed to discover if this starting point was being fostered and utilized within the program. Below is a summary of participant information: 
Table 1: Participant Demographic Information, Education and Activism Details

\begin{tabular}{|c|c|c|c|c|c|c|c|}
\hline \multirow{2}{*}{$\begin{array}{l}\text { Participant } \\
\text { ID }\end{array}$} & \multirow[b]{2}{*}{ Age } & \multirow[b]{2}{*}{ Sex } & \multirow{2}{*}{$\begin{array}{l}\text { Level of } \\
\text { Certification }\end{array}$} & \multirow[b]{2}{*}{ Stream } & \multicolumn{2}{|c|}{ Activist Identification } & \multirow[b]{2}{*}{ Teachable Subject } \\
\hline & & & & & Environment & Food & \\
\hline Alex & 19 & $\mathrm{~F}$ & $1 / S$ & Concurrent & Y & N & History \\
\hline Thea & 19 & $\mathrm{~F}$ & $\mathrm{P} / \mathrm{J}$ & Concurrent & N & N & $\mathrm{n} / \mathrm{a}$ \\
\hline Casey & 28 & $\mathrm{~F}$ & $\mathrm{P} / \mathrm{J}$ & Consecutive & Y & Y & $\mathrm{n} / \mathrm{a}$ \\
\hline Diana & 20 & $\mathrm{~F}$ & $\mathrm{~J} / \mathrm{I}$ & Concurrent & Y & N & English \\
\hline Ella & 20 & $\mathrm{~F}$ & $1 / S$ & Concurrent & Y & N & Environment/French \\
\hline Finn & 28 & $\mathrm{~F}$ & $1 / S$ & Consecutive & N & N & $\begin{array}{l}\text { Geography/ } \\
\text { Environmental }\end{array}$ \\
\hline Grace & 27 & $\mathrm{~F}$ & $1 / S$ & Consecutive & N & Y & French/German \\
\hline Holly & 43 & $\mathrm{~F}$ & $\mathrm{P} / \mathrm{J}$ & Concurrent & N & N & $\mathrm{n} / \mathrm{a}$ \\
\hline Isabelle & 23 & $\mathrm{~F}$ & $\mathrm{P} / \mathrm{J}$ & Consecutive & N & N & $\mathrm{n} / \mathrm{a}$ \\
\hline Sam & $X^{1}$ & $\mathrm{~F}$ & $\mathrm{P} / \mathrm{J}$ & Consecutive & Y & N & $\mathrm{n} / \mathrm{a}$ \\
\hline Smith & 24 & M & $1 / S$ & Concurrent & Y & N & Drama/History \\
\hline Kim & 1 & $\mathrm{~F}$ & $1 / S$ & Concurrent & Y & N & Geography/English \\
\hline Beth & 0 & $\mathrm{~F}$ & $P / J$ & Consecutive & N & $\mathrm{N}$ & $\mathrm{n} / \mathrm{a}$ \\
\hline
\end{tabular}

After the demographic information, each participant took part in two semi-structured interviews that lasted thirty to sixty minutes.

Pre-service teachers were asked questions in three areas: activism, environmental education, and food literacy. Questions revolved around definitions and understandings of these terms, in relation to teacher identity and pedagogy. Food literacy questions were as follows:

1) What role does food play in your pedagogy? Have you been involved in food education or related projects?

2) How do you define Food Literacy? Have you heard of this term, if so, where?

3) What is your experience in the pre-service program in relation to food literacy?

4) What is the relationship between food and environmental issues?

${ }^{1}$ Participant did not provide age 
5) Are you aware of the policy to integrate environmental education within your curriculum?

6) What barriers or opportunities do you see using food literacy within environmental education to aid in this integration?

The researcher audiotaped and fully transcribed each interview. NVivo, qualitative data analysis software, was used to code the emergent themes. After many readings, a list of non-repetitive and non-overlapping significant statements was coded from the transcripts (Holstein \& Gubrium, 1995). Themes within significant statements were then coded in NVivo. An example of a theme would be a mention of environmental education, under that term significant statements, including phrases such as interdisciplinary, were coded. Themes that were common among participants were grouped, allowing patterns to emerge, and each theme was considered individually. We then developed a written description of participants, including verbatim examples from the transcripts (Campigotto \& Barrett, 2017). As data analysis was ongoing, we continued to recruit participants until data saturation was reached. Validity was established by: providing transcripts and researcher notes to participants; allowing them to verify the text and clarify the meanings of their experiences; and having multiple sources for the same concept.

\section{Findings}

The following explores the findings of the study, including how pre-service teachers define and understand the concept of FL. Additionally, it suggests how they see relationships and connections between FL and EE and what suggestions they offer to improve and support their experiences of engaging in food pedagogy.

\section{Perspectives on food literacy}

Participants were asked to define the term Food Literacy, which was generally unfamiliar to preservice teachers (see Table 2). Four individuals could not define it. The other nine individuals had a range of understanding, most of which was limited to nutritional and consumption aspects. A few pre-service teachers could make more robust connections between food and environment, as well as social issues.

Specifically, most of the pre-service teachers interviewed (Casey, Diana, Ella, Sam, Grace, Holly, and Smith) included health and nutrition in their definitions. For example, Smith describes FL, in part, as "understanding food, what you are eating, what it is made of, what it is doing to your body." Casey, Ella, and Diane included field to table in their definitions. Casey noted that food literacy involved "being able to talk about food in a multifaceted way... have the language and a bit of an understanding that food just doesn't appear." 
Thea, Sam, Grace, and Holly connected FL to society and culture. Thea put it best saying that food is "a time where we all share things and talk... it is important because people spend a lot of time eating dinner and they converse during that time and conversations can be useful."

Only Thea, Casey, Ella, Grace, and Kim linked FL to environmental issues. Ella stated that "food issues and environmental issues go hand in hand." They related it to "different food issues like GMOs and factory farming". The fact that most participants did not link their definitions of FL to environmental issues is significant.

Indeed, based on the comprehensiveness of their definitions, Grace, Holly, Casey, and Sam seemed to have the most robust definitions of food literacy. Sam said that "it is about thinking about more... a bigger issue".

Table 2: Evidence of how teacher candidates define and understand the term Food Literacy

\begin{tabular}{|c|c|c|c|c|c|c|}
\hline \multirow{2}{*}{$\begin{array}{l}\text { Participant } \\
\text { Name }\end{array}$} & \multicolumn{6}{|c|}{ Evidence of interdisciplinary connection } \\
\hline & Field to table & Environment & Social/Cultural & $\begin{array}{l}\text { Equity/Social } \\
\text { justice }\end{array}$ & Health/nutrition & $\begin{array}{l}\text { Unable } \\
\text { to define }\end{array}$ \\
\hline $\begin{array}{l}\text { Alex, } \\
\text { Isabelle, } \\
\text { Finn, Beth }\end{array}$ & & & & & & $\begin{array}{l}\text { Could } \\
\text { not } \\
\text { define }\end{array}$ \\
\hline Thea & & $\begin{array}{l}\text { "I think the } \\
\text { food you eat } \\
\text { and the } \\
\text { choices that } \\
\text { you make } \\
\text { have an } \\
\text { impact on } \\
\text { things in the } \\
\text { environment" }\end{array}$ & $\begin{array}{l}\text { Food is "a time } \\
\text { where we all } \\
\text { share things and } \\
\text { talk... it is } \\
\text { important } \\
\text { because people } \\
\text { spend a lot of } \\
\text { time eating } \\
\text { dinner and they } \\
\text { converse during } \\
\text { that time and } \\
\text { conversations } \\
\text { can be useful" }\end{array}$ & & & \\
\hline Casey & $\begin{array}{l}\text { "...being able } \\
\text { to talk about } \\
\text { food in a } \\
\text { multifaceted } \\
\text { way... have } \\
\text { the language } \\
\text { and a bit of an } \\
\text { understanding } \\
\text { that food just } \\
\text { doesn't } \\
\text { appear" }\end{array}$ & $\begin{array}{l}\text { Food waste as } \\
\text { environmental } \\
\text { issue: "we } \\
\text { were able to } \\
\text { go through } \\
\text { the garbage } \\
\text { and see ok } \\
\text { how much of } \\
\text { this, like most } \\
\text { of it was food } \\
\text { waste...then } \\
\text { we created } \\
\text { compost } \\
\text { bins" }\end{array}$ & & & $\begin{array}{l}\text { FL is "the food we } \\
\text { need, what is good } \\
\text { for us" }\end{array}$ & \\
\hline
\end{tabular}




\begin{tabular}{|c|c|c|c|c|c|}
\hline Diana & $\begin{array}{l}\text { "where it } \\
\text { comes from, } \\
\text { where it is } \\
\text { going, how it } \\
\text { is made, and } \\
\text { who made it" }\end{array}$ & & & & $\begin{array}{l}\text { FL involves "reading } \\
\text { food labels" }\end{array}$ \\
\hline Ella & $\begin{array}{l}\text { "being able to } \\
\text { understand } \\
\text { and be aware } \\
\text { of where your } \\
\text { food is coming } \\
\text { from" }\end{array}$ & $\begin{array}{l}\text { "food issues } \\
\text { and } \\
\text { environmental } \\
\text { issues go } \\
\text { hand in } \\
\text { hand" Relates } \\
\text { to "different } \\
\text { food issues } \\
\text { like GMOs } \\
\text { and factory } \\
\text { farming" }\end{array}$ & & & $\begin{array}{l}\text { "what healthy } \\
\text { choices you have" }\end{array}$ \\
\hline Sam & & & $\begin{array}{l}\text { Retold } \\
\text { experience of } \\
\text { helping new } \\
\text { immigrants } \\
\text { access food and } \\
\text { poverty } \\
\text { associated with } \\
\text { immigration }\end{array}$ & $\begin{array}{l}\text { FL, } \\
\text { immigration, } \\
\text { and food } \\
\text { access "it is } \\
\text { about thinking } \\
\text { about more...a } \\
\text { bigger issue" }\end{array}$ & $\begin{array}{l}\text { Observed that } \\
\text { emergency food is } \\
\text { often the food } \\
\text { people don't want, } \\
\text { and is not healthy. "I } \\
\text { often feel it is a form } \\
\text { of exploitation and I } \\
\text { feel guilty about it" }\end{array}$ \\
\hline Grace & & $\begin{array}{l}\text { "If we can } \\
\text { create these } \\
\text { (fake meat) } \\
\text { why in the } \\
\text { world are we } \\
\text { using so } \\
\text { much CO2? } \\
\text { or losing out } \\
\text { on so much } \\
\text { space; we } \\
\text { could be } \\
\text { making crops } \\
\text { for other } \\
\text { areas that } \\
\text { have no } \\
\text { access good } \\
\text { soil for } \\
\text { producing } \\
\text { agriculture" }\end{array}$ & $\begin{array}{l}\text { "food is } \\
\text { wrapped up in } \\
\text { it, because as I } \\
\text { said, culture has } \\
\text { so much to do } \\
\text { with the daily } \\
\text { life and with } \\
\text { daily life comes } \\
\text { food practices" }\end{array}$ & $\begin{array}{l}\text { "we can bring } \\
\text { in these great } \\
\text { issues that are } \\
\text { facing every } \\
\text { aspect of } \\
\text { people" }\end{array}$ & $\begin{array}{l}\text { "Essentially reading a } \\
\text { label, like how many } \\
\text { carbs are in here, } \\
\text { how many fats" }\end{array}$ \\
\hline
\end{tabular}




\begin{tabular}{|c|c|c|c|c|}
\hline Holly & & $\begin{array}{l}\text { school poverty... } \\
\text { "prompted us to } \\
\text { do a culturally } \\
\text { aware food } \\
\text { bank" }\end{array}$ & $\begin{array}{l}\text { "Food equity is } \\
\text { critically } \\
\text { important to } \\
\text { me...So that } \\
\text { question or } \\
\text { conversation of } \\
\text { food issues } \\
\text { food equity } \\
\text { and global } \\
\text { issues" }\end{array}$ & $\begin{array}{l}\text { Introduced to it in } \\
\text { Physical } \\
\text { Education/Health }\end{array}$ \\
\hline Smith & & & & $\begin{array}{l}\text { "understanding } \\
\text { food, what you are } \\
\text { eating, what it is } \\
\text { made of what it is } \\
\text { doing to your body" }\end{array}$ \\
\hline Kim & $\begin{array}{l}\text { "I got a } \\
\text { chance to } \\
\text { explore it and } \\
\text { what it might } \\
\text { look like and } \\
\text { feel like to do } \\
\text { gorilla } \\
\text { gardening...I } \\
\text { am also } \\
\text { interested in } \\
\text { sustainable } \\
\text { food and } \\
\text { global food } \\
\text { system." }\end{array}$ & & $\begin{array}{l}\text { Has researched } \\
\text { "food justice" } \\
\text { Understands } \\
\text { the link } \\
\text { between } \\
\text { "Indigenous } \\
\text { rights or } \\
\text { Indigenous } \\
\text { forms of } \\
\text { education as } \\
\text { environmental } \\
\text { education" } \\
\text { and "social } \\
\text { justice" }\end{array}$ & \\
\hline
\end{tabular}

Some participants seemed interested in learning how to utilize food as a connecting concept in environmental issues, such as Grace who chose to do a project on culture and food, incorporating the idea of creating "fake" meat from stem cells and the resulting impact on food, culture and agriculture, or Finn who led a discussion on wasting water and its' environmental impact. Most pre-service teachers felt that the information was not available to support their learning on food. Ella explained that "education [courses] has not covered food at all". This finding mirrored a study implementing food literacy in Australia, where the majority of teachers appreciated the inclusion of food literacy and nutrition concepts in the new curriculum but doubted their ability to teach it without more training and resources (Nanayakkara et al., 2018).

The literature suggests that the school environment is only a minimal source of support for FL and focuses on cooking and food knowledge, often from personal endeavours and the family home (Colatruglio \& Slater, 2016). Ideally, FL needs to highlight a variety of skills and behaviours to "manage, select, prepare and eat foods to meet needs" and is used to empower communities (Vidgen \& Gallegos, 2014, p. 54). Only three individuals understood food as an interdisciplinary tool with some connection to environmental issues via culture, justice, and equity. They were able to share this knowledge in their teaching practicums. Ultimately, because of the teachers they were placed with, the placements in elementary and secondary schools 
viewed food in a charitable lens, which while necessary, did not include a discussion around the power and politics of why food charity is needed.

As shown in Table 2, pre-service teachers are seeking more connections and understanding within food literacy. Some were unable to define it, while others limited their definition to labels and healthy food. A few were able to make direct linkages to other environmental areas. Sam and Ella noted the connection they could make to gardening, activism, and food justice. One of the struggles for most educators is taking the theoretical knowledge, in this case using food as a window into environmental issues (Barndt, 2007), and putting it into practice. This is an area where the participants in this study felt they needed more exposure, resources, and support. The following discussion will explore the pedagogical lenses through which pre-service teachers encounter FL and how that affects their meaning-making development between FL and EE.

\section{Relationship between food literacy and environmental education}

As the literature suggests, there are numerous connections between food and the environment, and an understanding of such interconnectivity may provide a way to link curricular areas (Barndt, 2012; Johnston, 2008; Levkoe, 2006; Fawcett et al., 2002). While some pre-service teachers made connections between FL and EE there was some reluctance to name the two as interrelated (Grace, Isabelle). Pre-service teachers needed this connection elucidated regardless of how comfortable they were with food pedagogy. Isabelle noted, "Food is a part of it [environmental education] but it is not something that I think about all the time.... When I think about it [environment] I don't think of food first. It is kind of more separate in my mind. I definitely see and understand the connection between the two, but it is more something separate that I think about."

Likewise, Grace saw some connection between EE and FL but maintained the subjects as separate rather than integrated, "I think they are intrinsically linked, but I just think of them in a broader spectrum as being separate entities from which you can get to the same point. So, I would say yes, they are different focal points but of course there is a link. But in my experience, they are still separate."

This may be explained by educators' tendency to define or restrict certain ideas in separate subjects. A better understanding of food literacy and its role within environmental education may help break down some of those barriers making cross-curricular linkages and integration more seamless. 


\section{Food literacy in schools}

The participants experience with food in their practicum placements varied but many reported an absence of food literacy in the curriculum and discussion with mentor teachers. When food was mentioned, it was through the lens of deficiency and charity via breakfast and snack programs. In other words, food literacy tended to be defined through health and hunger. For example, Beth had no exposure to food literacy, or food in general. Casey took part in composting food waste at her practicum. On the other hand, Smith explained that he learned something new from his students about food. He recounted that while "we don't talk about food other than healthy food", he had a debate with students about organic versus non-organic. He said, "I learned something from the studies the students were bringing up. I have always been a huge pusher of organic but there was this study that one of the kids found on non-organic but still not processed. It was very interesting" (Smith).

In practicum, food was viewed primarily as a hunger issue. Pre-service teachers understood the need for breakfast or snack programs, but some realized that providing food was their only focus. A report by Sustain Ontario (2013) noted that students consume one third of their calories at school; thus, Sustain Ontario suggest schools should provide not only the opportunity to access healthy food but help students to develop knowledge and skills to learn about food in various capacities. Holly, at several points in the interviews, pointed out the lack of discussion regarding poverty and hunger, "There is no conversation. The school that I am in now... we have a women's shelter attached to the property. We have a lot of kids who are struggling but we don't even have a snack program. Which should be at the school, but it is not there."

She was quite upset that some kids had personal snacks "taken away" if they were "not considered healthy." This practice seemed to ignore the equity issues of poverty and hunger, since oftentimes unhealthy food is cheaper. Isabelle commented on the process of developing a snack program, referencing the Learning Opportunities Index (LOI) which ranks schools on factors such as family income and education (TDSB, 2020). She explained that,

My Mentor teacher was telling me about the rating scale they have for [school board] and it is out of 500 schools and if you are 1 it is the lowest [Learning Opportunity index] The school I am at right now is 56. So, they are at the low end. So, that is why they get a lot of extra programs [breakfast club and funding for food]. Another food related one is blessings in a bag. They have backpacks and families can sign up and you can get a bunch of food items in a bag. Each family gets a new one a week. I think it is so different from school to school, and school board to school board. (Holly)

Not only is it important for students to get adequate nutrition, but it is also important for them to understand the reasons behind the lack of access, the complexity of food from field to table, and the knowledge they need to make informed decisions about food (Jones, 2012). 
Isabelle explained that she had "personally only seen [these programs] happening and not talked about... They might have had an introduction about it, or newsletter, but I am not sure how much the children understand about what is going on."

Food literacy could have an enriching effect on the breakfast, snack, and backpack programs. The literature reports that student nutrition programs and food literacy, including food access programs and school gardens, have resulted in healthier eating, increasing knowledge of harvesting and preparing food, making positive lifestyle changes, and having better attitudes towards food (Anupama et al., 2008; Wittman et al., 2011). Diana believed that food access in schools was limited to "just distributing" the food and learning opportunities were lost by failing to discuss the need for it. As shown above, these programs can have an impact, but merely distributing food to students is not realizing the full potential of these initiatives.

Pre-service teachers provided some thoughts on how to expand the dialogue of food programs. Many focused on making explicit connections between existing curriculum and food issues. Finn and Smith discussed their personal desire to do food-related projects such as gardening, thus making a potential link to environmental education. Smith and Grace saw the possibility to connect food, geography, culture, and social justice in their teachable areas. Smith thought that "the easiest thing would be to do it in geography...there are whole sections in there about how we treat the environment and local resources and food and water." Grace made connections between food and culture that could be part of her French classes. She explained to me that "food is wrapped up in it, because as I said, culture has so much to do with the daily life and with daily life comes food practices." Grace also made connections to social justice. She explained, "If we are talking about social justice which we would do in an upper year class with French, then we can bring in these great issues that are facing every aspect of people. There doesn't have to be a limit when it comes to food. Everyone has to eat. How they eat, what they eat when they eat, all of these questions are fascinating, and people take it [the differences] for granted." (Grace)

Creating a conversation about food issues between students, teachers, and professors was viewed as a productive way to incorporate food into pedagogy. Drawing from an environmental science course, Thea thought a debate format would be useful. She explained that her class debated GMO foods,

\footnotetext{
"Where each person was designated a role, so one person was Monsanto, one group was farmers, some were the community. So, that was something that definitely brought my attention to food literacy, to see how it affected different parties and how different stakeholders are interested in the issues."
}

This conversation introduced the class to a variety of stakeholders and their concerns and possible actions. 
Another way to incorporate food literacy was to increase exposure to situations and conversations involving food, rather than just engaging with food related projects. Holly believed teachers should see students at lunch time to facilitate discussion of healthy and appropriate food. Holly believed that because teachers do not see their primary students at lunch, "there is less of a conversation about what they are eating and the impacts." She also believed that, while having a food drive was positive, her school was missing an opportunity to discuss other aspects. She explained, "Most schools do a food drive, you bring in whatever you want, and it goes to a food bank. So, we turned that around and talked about the community and how they need food and what their culture is in that area. So, we wanted to bring in specifics that they need." (Holly) Holly sought to meet the needs of the community and use it as a learning opportunity to make connections between why people needed these items and not just which ones.

Taking part in food preparation was also suggested. Grace believes food can be an "extracurricular" through "funding their own kitchen or nutrition class" ... "it just seems silly in this day and age, when we have that term...food literacy, why aren't we literate in our own high schools? Where great minds are starting to develop?" Lastly, Isabelle highlighted how play provided an opportunity for primary students to learn about health, "When they were playing with the food items in the kitchen centre one of the kids...the mentor teacher was like 'oh I am only going to eat the healthy one's what should I eat? [the teacher] makes it a teachable moment any time." (Isabelle)

Through the exploration of these experiences and ideas we can see that there lies some interest in FL. These discussions also highlight some connections to environmental education, such as justice, GMO's, cooking, and agriculture, although the pre-service teachers make the link explicitly. Interest exists in integrating food pedagogy as an experiential way of expanding the discussion on food programs and making connections to environmental issues within the curriculum. The interest and desire are present, but more support is needed from practicum schools and mentor teachers.

\section{EcoSchools}

Pre-service teachers felt that their exposure to EE was limited (Campigotto \& Barrett, 2017). The focus was typically on waste and recycling, the green movement and role of humans, and use of the outdoors. These were small initiatives within the school, with a wide range of acceptance and exposure to EE. Only one pre-service teacher felt they had a placement that connected EE with food via garden curriculum. The program teaches about "migration, habitat, hibernation" and Ella had the opportunity to take students "outside along the gardens so they can look at the shelter walk" and do some "place-based education."

EcoSchools seemed to be the main area pre-service teachers were offered an opportunity to work with EE and FL from a skill, preparation, and waste standpoint. Casey, Isabelle and Sam were all part of the EcoClub, and Holly, Smith, and Kim were at practicums with EcoSchools 
initiatives but were not part of the EcoClub; Thea attended a high school the previous year that had EcoSchools initiatives and took part in the EcoClub as a student.

In terms of EcoClub, supporting food pedagogy, one example is Casey, who with five students conducted a waste audit as part of the EcoClub. She explained, "we went through the school's garbage for a day...I think it was a valuable learning experience." She probed her students, asking "them what they noticed, and they said, the first thing was that there was a lot of food waste. Not only that, but there were things that were still in a package." The EcoClub provided this connection to students and was a platform for brainstorming solutions. She explained that this exercise,

Started a conversation, the kids thought they should tell parents that the [daycare children] should have more say in what they are eating, so that they would be more willing to eat their food. And I mentioned a rule that we had at my camp, 'take what you eat and eat what you take.' So, trying to think of ways we could reduce food waste. Maybe weighing the amount of food that is thrown away every day and having a prize for who lowers it... I know that they were getting compost bins when I was leaving. They didn't have enough for the entire school, but there would be some composting just not necessarily throughout. That was something they were starting. (Casey)

Waste was a running theme for pre-service teachers involved in the EcoClub. Sam explained that her role involved helping teachers run a contest, where the winning class would reduce their waste the most and receive a trophy. She recounted that the "entire school is getting involved" and "advocates go around once a week" to keep track of progress. She felt that "a lot is going on" in terms of EE and did not find it as limited in scope as Holly. Thea had experienced the EcoClub as a student in high school the year prior to her concurrent education degree. She explained that most initiatives focussed on "the amount of waste from the school" though she did describe that their students acted as advocates and did environmental presentations to elementary schools. Holly's criticism of the EcoSchool initiative coincided with her overall experience of $\mathrm{EE}$ in the classroom, which was negative in part due to a lack of support, in part because what was offered to students lacked depth. She believed teachers underestimated what students could understand, and limited conversation about food initiatives, for example, why there was limited culturally appropriate food collected in the food drives.

The biggest criticism of the EcoSchools initiatives was the limited conception displayed of EE and a frequent focus on making changes to the building, rather than the attitudes and values of administrators, teachers, and students. Sam valued the awareness raised with regular PA announcements and the involvement of the entire school, whereas Holly felt the teachers kept environmental discussion at a surface level. This latter critique was echoed in a study concluding that EcoSchools had no effect on students' environmental behaviors.

Students showed "lower utilization values," but without impact on preservation values which are responsible for changing environmental behaviors (Boeve-de Pauw \& Van Petegem, 2013). The 
experience of pre-service teachers in this study engages with similar themes regarding the lack of lasting change.

While the EcoClub served as a way for Casey to share her knowledge and passion with students, she felt these conversations "did not go beyond the doors of the EcoClub." Likewise, Holly noted that the EcoSchools program did not delve into issues effectively. The emphasis seemed to be on waste management and energy efficiency. She explained that "even with the schools that are gold certified or platinum level, it is only about the school. There may be touches of 'why do we recycle?' but not much else." This lack of connection to systemic issues mirrors what doesn't happen in food programming, the failure to embrace food literacy strategies to complement food provision in the schools.

\section{Discussion}

The goal of this study was to explore the contexts and supports needed for pre-service teachers to effectively teach food literacy and utilize the connection between EE and FL in their pedagogy and learning. To expand the connection between environment and food, the experiences of preservice teachers were explored. We found that while there was a high interest in the relationship between food and the environment, an overall lack of opportunity in both areas left a lot of room for improvement. This study focussed on relaying the authentic experience of its' participants, so the conclusions are drawn directly from pre-service teachers. Ultimately, pre-service teachers suggested improvements in the following areas: increased support in integrating personal experiences into the B.Ed. curriculum; providing opportunities to interact with food issues within the curriculum (i.e., courses, projects, concrete knowledge) and practicum placements; and expanding the way food is addressed in placement initiatives such as breakfast and snack programs and EcoSchools/EcoClub.

Pre-service teachers indicated a need for integrating personal passions, environmental education, and food literacy. Pre-service teachers value their experiences and are already reflecting on how these experiences can be incorporated into the classroom but need further direction and support from their educators and mentors. One recommendation was changes to curriculum and spaces for communication and exploration. What pre-service teachers wanted was the creation of a community of practice, with avenues to talk about personal experiences, share resources about food literacy, evaluate policies within the classroom and develop strategies to address them (Daniel et al., 2013). They wanted a hands-on, minds-on approach to explore, much like they would implement with their own students. As some noted, being given the authority and choice to focus on environmental topics, including food, for presentations was a small step; other studies have also found this to be a successful strategy, especially when preservice teachers were given resources applicable to their subject matter (Buchanan, 2012).

The importance of reviewing the pre-service curriculum is important due to the potential of a multiplier effect, as what pre-service teachers learn and are encouraged to learn may trickle 
down to their own students. Likewise, teacher education can influence several pre-service teachers, in turn changing the resulting pedagogy in the classroom (Powers, 2004). An integrated curriculum for pre-service teachers moves away from education strategies confined to subjects, helps new teachers enrich their teaching philosophy, and prevents the "tack it on approach" that environmental issues are saddled with in the curriculum; EE can then be rooted in local places with long term goals thus illuminating the benefits of using food as a lens to approach EE (Powers, 2004). There is some support for an integrated curriculum to teach EE, the benefits of which include authentic learning, applicable "real world" links between the curriculum and students' lives - which provide a rich connection to food and eating, promotion of community and collaboration, and improved relationships between teaches and students - and increased success in subject areas such as math and literacy (Lieberman \& Hoody, 1998; Bozzelli, 1999).

Lastly, most of the experiences with FL came from school initiatives such as breakfast programs and EcoSchool initiatives such as the EcoClub. These programs were accessible to preservice teachers since they were often recruited to volunteer, and it is a familiar program from their own schooling. As noted, Casey, Isabelle and Sam were all part of the EcoClub and Holly, Smith, and Kim were at practicums with EcoSchools initiatives but were not personally involved. For this study, that accounts for half of the pre-service teachers. The effectiveness of EcoSchools were criticized by participants. EcoSchools focus on goals that are attainable in each context, such as recycling but often limit the discussion of food to "waste management", like compost and not wasting food from lunch. The program could make a connection to the document "Acting Today, Shaping Tomorrow" and fulfill the goal of linking with community organizations to expand and enrich EE and FL in the classroom (Ontario Ministry of Education, 2009). Providing pre-service teachers with the materials and knowledge to expand discussions about systemic issues of why food should not be wasted, and why food is provided via a breakfast program would be more beneficial. Ultimately, while some pre-service teachers had knowledge in food pedagogy, they lacked the support needed to integrate it into their teaching. Implementation of their suggestions may capitalize on their interest and help solidify connections in learning to realize these connections in practice.

\section{Conclusion}

This study asked, can FL be used as an integrative tool for EE and if so, what supports are needed for pre-service teachers? What is the relationship between EE and FL? There seemed to be interest in learning how to utilize food to connect environmental issues, but unfortunately preservice teachers were generally unable to implement this without further support. FL was generally an unfamiliar or limited term to pre-service teachers.

Overall, a limited exposure to FL was found in the B.Ed. program and during practice teaching, food was explored minimally through food waste in the EcoClub or within snack programs. There was a high interest to include EE and FL, but even with previous experiences and passions 
in this area support was still needed. This study was limited to the perceptions of pre-service teachers. This point in a teachers' learning journey serves as an opportunity for intervention to help foster more understanding, theoretical study, and practical implementation of FL ideas in the classroom. While these data were viewed as authentic experiences between the researcher and the participants it is still self-reported. Further studies that evaluate the effectiveness and impact of courses that focus on FL and EE at the pre-service level should be conducted. To "deepen" the conversation with pre-service teachers and to address EE and FL in schools, it is imperative to continue the conversation with new voices and experiences (Hart, 2003). This could include a study with professors of education, practicing teachers and those who create curriculum. This study does provide authentic voices and can be used to expand on studies of curriculum assessment such as the data found in Buchanan (2012). A large-scale study could ensure the sharing of voices and beliefs of pre-service teachers, teachers, professors in education through a qualitative lens.

Utilizing the suggestions for support made by pre-service teachers in this study, a variety of avenues can be explored and evaluated for their effectiveness in terms of creating a community of practice for pre-service environmental educators (Daniel et al., 2013). Ultimately, the pre-service program could capitalize on the general knowledge of EE and FL and help create knowledge sharing communities via forums, events, and project-based learning. The curriculum at the B.Ed. level could also mirror the intentions of policies to integrate EE. As pre-service teachers in this study noted, authentic hands-on and "experiential experiences" were lasting and made an impact (Alex, Smith, Thea). Spaces to explore EE could also be extracurricular, though one study found this approach to have a low level of participation among Ontario pre-service teachers at one site due to the connection between "average" environmental knowledge and "average" desire to actively participate in environmental initiatives (Gwekwerere, 2014). A focus on action is often needed to make lasting connections (Gwekwerere, 2014) that empowers both students and teachers, which could include the uptake of environmental projects in their practice teaching, or a closer exploration of the interconnections between EE and FL within existing curriculum. Such innovations, platforms and curricula could help fill the gaps for those educators interested in upholding the EE integration policy and use FL as a tool to make these connections.

Acknowledgements: We would like to acknowledge the experiences of pre-service teachers interviewed for this study

\section{References}

Anderson, A. (2007). Nutrition interventions in women in low-income groups in the U.K. Proceedings of the Nutrition Society, 66(1), 25-32. https://doi.org/10.1017/s0029665107005265 
Anupama, J., Misako Azuma, A., \& Feenstra, G. (2008). Do farm-to-school programs make a difference? Findings and future research needs. Journal of Hunger and Environmental Nutrition,3(2-3), 229-246. https://doi.org/10.1080/19320240802244025

Barndt, D. (2012). Catalyzing creativity: Education and art feed the food justice movement. In M. Koc, J. Sumner, \& A. Winson (Eds.), Critical Perspectives in Food Studies (pp. 65-84). Oxford University Press.

Barrett, M. J. (2007). Homework and fieldwork: investigations into the rhetoric-reality gap in environmental education research and pedagogy. Environmental Education Research, 13(2), 209-223. https://doi.org/10.1080/13504620701284928

Barrett, S. E. (2013). Becoming an activist science teacher: A longitudinal study of an induction intervention. Electronic Journal of Science Education, 17(4), 151-164. https://doi.org/10.1007/978-94-6209-557-1_10

Barrett, S. E. (2017). "Wealth that I can't even imagine": The relevance of social class in new teacher induction. In B. Kutsyuruba \& K. Walker (Eds.), The bliss and blisters of early career teaching: A pan-Canadian perspective (pp. 47-63). Word \& Deed Publishing.

Boeve-de Pauw, J., \& Van Petegem, P. (2013). A cross-cultural study of environmental values and their effect on the environmental behavior of children. Environment and Behavior, 45(5), 551-583. https://doi.org/10.1177/0013916511429819

Bozzelli, E. (1999). ROC 1998 and Horwood's model of integrated programmes. Pathways: Ontario Journal of Outdoor Education, 11(2), 24-26.

Breunig, M., \& O’Connell, T. S. (2008). An overview of outdoor experiential education in Canadian K-12 schools: What has been and what is. Taproot: A Publication of the Coalition for Education in the Outdoors, 18(1), 10-16.

Breunig, M., Murtell, J., Russell, C., \& Howard, R. (2014). The impact of integrated environmental studies programs: are students motivated to act pro-environmentally? Environmental Education Research, 20(3), 372-386. https://doi.org/10.1080/13504622.2013.807326

Brodie, R. (2017). Experiences of secondary school teachers, students, and administrators in one exemplary EcoSchool: A description of successful practices and challenges [Unpublished master's thesis). Brock University.

Brown, B., \& Hermann, J. (2005). Cooking classes increase fruit and vegetable intake and food safety behaviours in youth and adults. Journal of Nutrition Education and Behaviour, 37(2), 104-5. https://doi.org/10.1016/s1499-4046(06)60027-4

Buchanan, J. (2012). Sustainability education and teacher education: Finding a natural habitat? Australian Journal of Environmental Education, 28(2), 108-124.

Campigotto, R., \& Barrett, S. E. (2017). Creating space for teacher activism in environmental education: Pre-service teachers' experiences. Canadian Journal of Environmental Education, 22, 42-57. 
Classens, M., \& Sytsma, E. (2020). Student food literacy, critical food systems pedagogy, and the responsibility of postsecondary institutions. Canadian Food Studies, 7(1), 8-19. https://doi.org/10.15353/cfs-rcea.v7i1.370

Colatruglio, S., \& Slater, J. (2016). Challenges to acquiring and utilizing food literacy: Perceptions of young Canadian adults. Canadian Food Studies / La Revue Canadienne Des études Sur l'alimentation, 3(1), 96-118. https://doi.org/10.15353/cfs-rcea.v3i1.72

Creswell, J. W., \& Miller, D. L. (2000). Determining validity in qualitative inquiry. Theory Into Practice, 39 (3), 124-130.

Creswell, J. W. (2013). Qualitative inquiry \& research design: Choosing among five approaches (Vol. 3). SAGE.

Cullen, T., Hatch, J., Martin, W., Higgins, J. W., \& Sheppard, R. (2015). Food literacy: Definition and framework for action. Canadian Journal of Dietetic Practice and Research, 76(3), 140-145. https://doi.org/10.3148/cjdpr-2015-010

Cutter, A., \& Smith, R. (2001). Gauging primary school teachers' environmental literacy: An issue of priority. Asia Pacific Education Review, 2(2), 45-60.

Daniel, G., Auhl, G., \& Hastings, W. (2013). Collaborative feedback and reflection for professional growth: preparing first-year pre-service teachers for participation in the community of practice. Asia-Pacific Journal of Teacher Education, 41(2), 159-172. https://doi.org/10.1080/1359866X.2013.777025

Elsden-Clifton, J., \& Futter-Puati, D. (2015). Creating a health and sustainability nexus in food education: Designing third spaces in teacher education. Australian Journal of Environmental Education, 31(1), 86-98. doi:10.1017/aee.2014.44

Evans, N., Whitehouse, H., \& Hickey, R. (2012). Pre-service teachers' conceptions of education for sustainability. Australian Journal of Teacher Education, 37(7), 1-12.

Fawcett, L., Bell, A., \& Russell, C. (2002). Guiding our environmental praxis: Teaching and learning for social and environmental justice. In W. Filho (Ed.), Teaching sustainability at universities: Towards curriculum greening: Environmental Education, communication and sustainability (pp. 223-238). Peter Lang Scientific Publishers.

Flowers, R., \& Swan, E. (2012). Introduction: Why food? What pedagogy? Why adult education? Australian Journal of Adult Learning, 52(3), 419-433.

Frisch, A. L., Camerini, L., Diviani, N., \& Schulz, P. J. (2012). Defining and measuring health literacy: how can we profit from other literacy domains? Health Promotion International, 27(1), 117-126. https://doi.org/10.1093/heapro/dar043

Mita, S. C., Gray, S. A., \& Goodell, L. S. (2015). An explanatory framework of teachers' perceptions of a positive mealtime environment in a preschool setting. Appetite. 90(37), 44. http://doi.org/10.1016/j.appet.2015.02.031. Epub 2015 Feb 26. PMID: 25728886

Gwekwerere, Y. (2014). Pre-service teachers' knowledge, participation and perceptions about environmental education in schools. Australian Journal of Environmental Education, 30(2), 198-214. 
Haugen, C. S. (2010). Adult learners and the environment in the last century: A historical analysis of environmental adult education. Electronic Green Journal, 29, 1-14.

Holstein, J., \& Gubrium, J. (1995). The active interview (Vol. 37). SAGE.

Johnston, J. (2008). The citizen-consumer hybrid: Ideological tensions and the case of Whole Foods Market. Theory and Society, 37(3), 229-270. https://doi.org/10.1007/s11186-007$\underline{9058-5}$

Jones, M. D. (2012). Engaging secondary school students in food-related citizenship: Achievements and challenges of a multi-component programme. Educational Sciences, 2, 77-90.

Jordan, N., Grossman, J., Lawrence, P., Harmon, A., Dyer., W., Maxwell, B., Cadieux, K. V., Galt, R., Rojas, A., Byker, C., Ahmed, S., Bass, T., Kebreab, E., Sing, V., Micheals, T., \& Tzenis, C. (2014). New curricula for undergraduate food -systems education: A sustainable agriculture education perspective. NACTA Journal, 58(4), 302-310.

Knobloch, N. A. (2008). Factors of teacher beliefs related to integrating agriculture into elementary school classrooms. Agriculture and Human Values, 25(4), 529-539. http://dx.doi.org/10.1007/s10460-008-9135-z

Lang, T., \& Caraher, M. (2001). Is there a culinary skills transition? Data and debate from the UK about changes in cooking culture. Journal of the Home Economics Institute of Australia, 8(2), 2-14.

Levkoe, C. (2006). Learning democracy through food justice movements. Agriculture and Human Values, 23, 89-98. https://doi.org/10.1007/s10460-005-5871-5

Lieberman, G., \& Hoody, L. (1998). Closing the achievement gap: Using the environment as an integrating context for learning. San Diego CA: State Education and Environment Roundtable

Meehan, M., Yeh, M., \& Spark, A. (2008). Impact of exposure to local food sources and food preparation skills on nutritional attitudes and food choice among minority youth. Journal of Hunger \& Environmental Nutrition, 3(4), 456-471. http://dx.doi.org/10.1080/19320240802529383

Nanayakkara, J., Margerison, C., \& Worsley, A. (2018). Teachers' perspectives of a new food literacy curriculum in Australia. Health Education, 118(1), 48-61. http://dx.doi.org/10.1108/HE-05-2017-0024

Ontario EcoSchools. (2019). What is certicication? https://ecoschools.ca/about/what-iscertification/

Ontario Ministry of Education. (2007). The Ontario curriculum grades 1-8: Science and technology.http://www.edu.gov.on.ca/eng/curriculum/elementary/scientec18currb.pdf

Ontario Ministry of Education. (2009). Acting today, shaping tomorrow: A policy framework for environmental education in Ontario schools. Ministry of Education. www.edu.gov.on.ca.

Ontario Student Nutrition Program. (2016). About us. Student nutrition program. https://www.ontario.ca/page/student-nutrition- 
program\#: :text=in $\% 20$ your\%20community.,About $\% 20$ the $\% 20$ Student $\% 20$ Nutrition\%20Program,helps $\% 20$ kids $\% 20$ learn $\% 20$ and $\% 20 \mathrm{f}$ ocus.

Powers, A. L. (2004). Teacher preparation for environmental education: Faculty perspectives on the infusion of environmental education into preservice methods courses. The Journal of Environmental Education, 35(3), 3-11. https://psycnet.apa.org/doi/10.3200/JOEE.35.4.1732

Rogan, K. (1999). School-based environmental programming: Barriers and experiences. Research conducted for the J.W. McConnell Family Foundation.

Russell, C., \& Burton, J. (2000). A Report on an Ontario Secondary School Integrated Environmental Studies Program. Canadian Journal of Environmental Education, 287-303.

Short, F. (2003). Domestic cooking skills - What are they? Journal of Home Economics Institute of Australia, 10(3), 13-22.

Stevenson, R. (2007). Schooling and environmental/sustainability education: from discourses of policy and practice to discourses of professional learning. Environmental Education Research, 13(2), 265-285. https://doi.org/10.1080/13504620701295650

Stevenson, R., Wals, A., Dillon, J., \& M. Brody (2013). Introduction: An orientation to environmental education and the handbook. In R. Stevenson, M. Brody, J. Dillon, \& A. Wals, International Handbook of Research on Environmental Education (pp. 1-576). New York: Routledge Publishers.

Stir, J. (2006). Restructuring teacher education for sustainability: Student involvement through a 'strengths model'. Journal of Cleaner Production, 14, 830-836. http://dx.doi.org/10.1016/j.jclepro.2005.11.051

Sumner, J. (2013). Food literacy and adult education: Learning to read the world by eating. The Canadian Journal for the Study of Adult Education, 2(25), 79-92.

Sustain Ontario (2013). Backgrounder on food literacy, food security and local food procurement in Ontario's schools. Ontario Edible Education Network. http://sustainontario.com/wp2011/wpcontent/uploads/2011/02/SustainOntario_EducationBackgrounder_Oct20131.pdf.

Thompson, G. (2004). Environmental Education in Alberta: barriers and bridges, EECOM News. Canadian Association of Environmental Education and Communication, 3.

Toronto District School Board (TDSB) (2020). Learning opportunities index (LOI): Research and development. https://www.tdsb.on.ca/research/research/learning-opportunities-index

Truman, T., Lane, D., \& Elliott, C. (2017). Defining food literacy: A scoping review. Appetite, 116(1), 365-371. https://doi.org/10.1016/j.appet.2017.05.007

Tuncer, G., Tekkaya, C., Sungur, S., Cakiroglu, J., Ertpinar, H., \& Kaplowitz, M. (2009). Assessing pre-service teachers' environmental literacy in Turkey as a means to develop teacher education programs. International Journal of Educational Development, 29(4), 426-436. https://doi.org/10.1016/j.ijedudev.2008.10.003 
Valley, W., Wittman, H., Jordan, N., Ahmed, S., \& Galt, R. (2017). An emerging signature pedagogy for sustainable food systems education. Renewable Agriculture and Food Systems, 33(5), 476-480.

Vidgen, H., \& Gallegos, D. (2014). Defining food literacy and its components. Appetite, 76, 5059. https://doi.org/10.1016/j.appet.2014.01.010

Wittman, H., Desmarais, A., \& Wiebe, N. (2011). Food Sovereignty in Canada: Creating Just and Sustainable Food Systems. Fernwood Publishing. 